\title{
MÉTODO DE APLICAÇÃO DO ÁCIDO INDOLBUTÍRICO NA ESTAQUIA DE CULTIVARES DE PESSEGUEIRO ${ }^{1}$
}

\author{
MAURO BRASIL DIAS TOFANELLI ${ }^{2}$ \\ JOÃO DOMINGOS RODRIGUES ${ }^{3}$ \\ ELIZABETH ORIKA ONO ${ }^{4}$
}

\begin{abstract}
RESUMO - Conduziu-se este trabalho com o objetivo de avaliar o potencial de propagação vegetativa de estacas semilenhosas de cultivares de pessegueiro tratadas com ácido indolbutírico (AIB) em dois métodos de aplicação. O experimento foi desenvolvido no Departamento de Botânica do Instituto de Biociências, Universidade Estadual Paulista "Júlio de Mesquita Filho" (UNESP), campus de Botucatu (SP). De ramos coletados de plantas-matrizes das cultivares Delicioso Precoce, Jóia 1 e Okinawa, estacas semilenhosas foram preparadas com 10 a $15 \mathrm{~cm}$ de comprimento, diâmetro de 5 $\mathrm{mm}$ e desprovidas de folhas e foram submetidas aos tra-
\end{abstract}

tamentos de imersão rápida por 5 segundos em soluções concentradas $\left(0,1250,2500\right.$ e $3750 \mathrm{mg}^{-L^{-1}}$ de AIB) e imersão lenta por 24 horas em soluções diluídas $(0,100$, 200 e 300mg. $\mathrm{L}^{-1}$ de AIB). Posteriormente, foram plantadas em bandejas de poliestireno expandido, utilizando-se vermiculita de granulometria fina como substrato e colocadas em estufa sob nebulização intermitente por 45 dias. A cultivar Okinawa (29\%) e o método de imersão rápida em AIB (9\%) proporcionaram os melhores resultados de enraizamento. Não se recomenda a propagação das cultivares de pessegueiro Delicioso Precoce, Jóia 1 e Okinawa em estacas semilenhosas.

TERMOS PARA INDEXAÇÃO: Prunus persica, propagação vegetativa, regulador de crescimento, AIB.

\section{APPLICATION METHODS OF INDOLEBUTIRIC ACID IN CUTTING ROOTING ON PEACH CULTIVARS}

\begin{abstract}
This work had as objective to evaluate the vegetative propagation potential of semihardwood cuttings of peach cultivars treated with indolebutyric acid (IBA) at two different application methods. The trial was carried out at the Departamento de Botânica/Instituto de Biociências of the Universidade Estadual Paulista "Júlio de Mesquita Filho" (UNESP), located in Botucatu (SP, Brazil). The cuttings were prepared of stems taken from Delicioso Precoce, Jóia 1 and Okinawa peach cultivars in December, 2001. The
\end{abstract}

cuttings were treated with $0 ; 1,250 ; 2,500$ and $3,750 \mathrm{mg}$ $\mathrm{L}^{-1}$ IBA for 5 seconds (concentrated solutions) and 0 , 100, 200, 300mg L $\mathrm{m}^{-1}$ IBA for 24 hours (diluted solutions), and were planted in polystyrene trays using vermiculite as substrate, and put into the greenhouse under intermittent mist condition for 45 days. The best results of rooting were obtained with cultivar Okinawa $(29 \%)$ and with IBA concentrated solutions $(9 \%)$. The results showed that the peach cultivars propagation by cuttings is not recommended.

INDEX TERMS: Prunus persica, vegetative propagation, growth regulator, IBA.

\section{INTRODUÇÃO}

No Brasil, o pessegueiro (Prunus persica (L.) Batsch) é cultivado, principalmente, na região Sul; porém, a região Sudeste vem demonstrando crescente expressão no volume total de pêssego produzido no país.

$\mathrm{O}$ aumento na disponibilidade de mudas de qualidade é essencial para alcançar patamares ain- da maiores na produção dessa fruta, bem como na ampliação dos pomares brasileiros com essa frutífera. Existe tendência de instalação de pomares de pessegueiro de alta densidade (Kluge et al., 2001); conseqüentemente, haverá aumento na necessidade de grande produção, o que poderá ser alcançado por meio da estaquia (Avery e Beyl, 1991).

1. Parte da Tese apresentada à Universidade Estadual Paulista "Júlio de Mesquita Filho" pelo primeiro autor, para obtenção do Título de Doutor em Agronomia/Fitotecnia.

2. Engenheiro Agrônomo, MSc, Doutorando-DPV/FCA/UNESP, Botucatu, SP, Professor, Faculdade de Agronomia/FIMES, Caixa Postal 104, 75830-000 - Mineiros, GO.

3. Bióloga, Doutora, Professora do Departamento de Botânica-IBB/UNESP, Botucatu, SP.

4. Engenheiro Agrônomo, Doutor, Professor Titular do Departamento de Botânica, IBB/UNESP. 
A propagação do pessegueiro é baseada na enxertia de borbulhas de cultivares-copa sobre portaenxertos obtidos por sementes (TOFANELLI et al., 2001; RUFATO e KERSTEN, 2000). Mas, esse método de propagação é vantajoso para regiões próximas das indústrias de processamento, onde a obtenção dos caroços é mais prática (BIASI et al., 2000). Mesmo assim, a propagação convencional do pessegueiro apresenta alguns inconvenientes, como risco de segregação genética dos porta-enxertos, maior tempo para produção de mudas e necessidade de mão-de-obra especializada para operação de enxertia (TOFANELLI, 1999). Já a propagação do porta-enxerto em estacas é justificada pela uniformidade da descendência e facilidade de produção da muda, por dispensar a enxertia, diminuindo o custo e o tempo para sua obtenção (CHALFUN e HOFFMANN, 1997).

Diversos são os trabalhos desenvolvidos para verificar a capacidade de enraizamento de estacas de pessegueiro, no entanto, os resultados têm sido contraditórios.

Normalmente, é necessária a aplicação exógena de reguladores vegetais em estacas de pessegueiro, objetivando-se aumentar o percentual de enraizamento. $O$ ácido indolbutírico (AIB) é um dos mais utilizados (FINARDI, 1998), pois é fotoestável, não é tóxico em uma ampla faixa de concentração e não é degradado pela ação biológica (HOFFMANN et al., 1996; COUTINHO et al., 1991). Porém, o método ideal de aplicação ainda não é bem definido para cada espécie ou cultivar.

Couvillon e Erez (1980) demonstraram aumentos significativos no enraizamento quando aplicaram AIB em estacas de pessegueiro da cultivar Texas A-170. Obtiveram apenas $9,8 \%$ de estacas enraizadas quando não aplicaram o regulador e 95, 96,2 e 100\% quando aplicaram as respectivas concentrações de 1500, 2500 e $3500 \mathrm{mg} . \mathrm{L}^{-1}$ de AIB em imersão por 5 segundos. Já Chalfun et al. (1994) observaram efeito do AIB aplicado nas concentrações de $0,50,100$ e $200 \mathrm{mg} . \mathrm{L}^{-1}$ em imersão por 24 horas de estacas de pessegueiro da cultivar Okinawa. Esses autores encontraram 100\% de enraizamento na concentração de $130,25 \mathrm{mg} \mathrm{L}^{-1}$ de AIB.

Com este trabalho objetivou-se avaliar o efeito do método de aplicação do AIB no enraizamento de estacas semilenhosas de cultivares de pessegueiro e estudar a possibilidade de propagar vegetativamente essa frutífera em estacas.

\section{MATERIAL E MÉTODOS}

O experimento foi conduzido no Departamento de Botânica do Instituto de Biociências, Universidade
Estadual Paulista "Júlio de Mesquita Filho" (UNESP), campus de Botucatu (SP), no período de dezembro de 2001 a janeiro de 2002.

Em 12 de dezembro de 2001, foram coletados ramos semilenhosos de pessegueiro das cultivares-copa Delicioso Precoce e Jóia 1 e o porta-enxerto Okinawa de plantas-matrizes instaladas no pomar da Coordenadoria de Assistência Técnica Integral (CATI), localizado no município de Itaberá (SP) a uma distância de 172 $\mathrm{Km}$ de Botucatu. Os ramos foram coletados e colocados em baldes com água para evitar a desidratação, onde permaneceram até a chegada em Botucatu. Da porção mediana dos ramos, foram preparadas as estacas com 10 a $15 \mathrm{~cm}$ de comprimento, diâmetro médio de $5 \mathrm{~mm}$ e quatro gemas por estaca, sendo efetuado um corte horizontal na base e em bisel na extremidade superior, ambos os cortes realizados próximos a uma gema. Não foram mantidas folhas nas estacas por causa da alta infestação de ferrugem (Transchelia discolor).

Para realização dos tratamentos com AIB, as bases das estacas foram recortadas a $3 \mathrm{~mm}$ da extremidade para evitar os efeitos da oxidação de compostos fenólicos e imersas, aproximadamente, a $3 \mathrm{~cm}$ da sua base em soluções de $0,1250,2500$ e 3750 mg.L $\mathrm{L}^{-1}$ de AIB por 5 segundos (soluções concentradas), constituindo o tratamento de imersão rápida, ou em $0,100,200$ e 300 mg. $\mathrm{L}^{-1}$ de AIB por 24 horas (soluções diluídas), constituindo o tratamento de imersão lenta. Durante o tratamento imersão lenta em AIB, as estacas permaneceram imersas nas soluções em estufa com ventilação controlada. O preparo das soluções de AIB foi realizado diluindo-se o regulador na forma de pó em $5 \mathrm{ml}$ de álcool comum $\left(98^{\circ} \mathrm{GL}\right)$, para as concentrações do tratamento lento, e em $20 \mathrm{ml}$ de álcool, para as concentrações do tratamento rápido, sendo ambas as diluições completadas com água destilada até $1 \mathrm{~L}$. Após a aplicação do $\mathrm{AIB}$, as estacas foram plantadas em bandejas de poliestireno expandido com 72 células, utilizando vermiculita de granulometria fina como substrato e colocadas para enraizar em estufa, sob nebulização intermitene, durante 45 dias.

O delineamento experimental adotado foi o inteiramente casualizado com três repetições por parcela e doze estacas por repetição, em esquema fatorial $3 \times 2$ constituído pelas três cultivares e pelos dois métodos de aplicação de AIB.

As variáveis analisadas foram as porcentagens de enraizamento, de brotação, estacas mortas, com formação de calo, número médio de raízes primárias e comprimento médio da maior raiz.

Ciênc. agrotec., Lavras. V.27, n.5, p.1031-1037, set./out., 2003 
As análises estatísticas foram realizadas comparando-se as médias pelo teste Duncan com nível de significância de 5\%. Quando necessário, realizou-se regressão polinomial para estudo do efeito das concentrações de AIB. Efetuou-se a transformação de dados segundo a equação arco seno $\sqrt{x / 100}$ para os dados em porcentagem e $\sqrt{x+1}$ para os dados de contagem.

\section{RESULTADOS E DISCUSSÃO}

Em todas as variáveis, com exceção da variável percentual de estacas mortas, houve efeito da cultivar, do método de aplicação do AIB; no entanto, não houve efeito da interação. Em todas variáveis, a cultivar Okinawa foi superior às cultivares Delicioso Precoce e Jóia 1 (Tabela 1). Com relação ao método de aplicação, apenas na porcentagem de brotação houve superioridade do tratamento das estacas por imersão lenta em AIB. A maior formação de brotos obtida nas estacas tratadas com soluções diluídas pode também ter contribuído para o menor enraizamento demonstrado neste tratamento, pois, conforme Hartmann e Kerster (1990), citados por Antunes et al. (1996), a brotação antes do enraizamento é prejudicial à formação de raízes nas estacas em razão do consumo de reservas.
A diferença da capacidade de enraizamento de estacas entre cultivares de pessegueiro é mencionada em diversos trabalhos, como o desenvolvido por Fachinello et al. (1984), nos quais demonstrou-se que as cultivares Capdebosq e Convênio foram superiores à Diamante quanto à formação de raízes em estacas lenhosas. Okie (1984) constatou a superioridade da cultivar de pessegueiro Siberian C $(80 \%)$ em relação às cultivares Halford $(56 \%)$ e Lovell (64\%) quanto à capacidade de enraizamento de estacas. De acordo com Rufato e Kersten (2000), o potencial genético de enraizamento de cada cultivar é a principal explicação para a diferença de percentuais de estacas enraizadas entre as cultivares BR2 e Esmeralda. Discordando desses resultados, Dutra et al. (1999) não encontraram diferenças significativas nos percentuais de estacas semilenhosas enraizadas entre as cultivares de pessegueiro BR-2, Capdebosq e Diamante, quando as trataram com 0, 1000, 2000, 3000 e $4000 \mathrm{mg} . \mathrm{L}^{-1}$ de AIB. Com as mesmas cultivares e dosagens de AIB, Dutra et al. (2002) constataram diferença no potencial de enraizamento das estacas coletadas na primavera e no verão, obtendo-se melhores resultados com a cultivar Capdeboscq e aumento do percentual de estacas enraizadas até a concentração de $3000 \mathrm{mg} . \mathrm{L}^{-1}$ de AIB em todas cultivares.

TABELA 1 - Porcentagem de enraizamento, de brotação, estacas com formação de calo, número médio de raízes primárias e comprimento médio da maior raiz, de estacas semilenhosas de pessegueiro cvs. Delicioso Precoce, Jóia 1 e Okinawa, tratadas com imersão lenta e rápida de diferentes concentrações de AIB. Botucatu-SP, $2002^{(1)}$.

\begin{tabular}{llccccc}
\hline Fator & Níveis do fator & $\begin{array}{c}\text { Enraizamento } \\
(\mathbf{\%})\end{array}$ & $\begin{array}{c}\text { Brotação } \\
(\mathbf{\%})\end{array}$ & $\begin{array}{c}\text { Formação } \\
\text { de calo } \\
(\boldsymbol{\%})\end{array}$ & $\begin{array}{c}\text { Número médio } \\
\text { de raízes } \\
\text { primárias }\end{array}$ & $\begin{array}{c}\text { Comprimento } \\
\text { médio da } \\
\text { maior raiz } \\
(\mathbf{c m})\end{array}$ \\
\hline \multirow{2}{*}{ Cultivar } & Jelicioso Precoce & $0,3 \mathrm{~b}$ & $39,1 \mathrm{c}$ & $0,3 \mathrm{~b}$ & $0,3 \mathrm{~b}$ & $0,1 \mathrm{~b}$ \\
& Jóia 1 & $0,8 \mathrm{~b}$ & $52,9 \mathrm{~b}$ & $0,8 \mathrm{~b}$ & $0,3 \mathrm{~b}$ & $0,3 \mathrm{~b}$ \\
\hline Método de & Imersão lenta & $29,0 \mathrm{a}$ & $70,3 \mathrm{a}$ & $30,4 \mathrm{a}$ & $2,1 \mathrm{a}$ & $1,7 \mathrm{a}$ \\
\hline aplicação & Imersão rápida & $9,0 \mathrm{~b}$ & $63,1 \mathrm{a}$ & $3,2 \mathrm{~b}$ & $0,5 \mathrm{~b}$ & $0,3 \mathrm{~b}$ \\
\hline
\end{tabular}

${ }^{(1)}$ Médias seguidas por letras distintas na linha, diferem entre si pelo teste Duncan ao nível de $5 \%$ de significância. 
Embora a aplicação exógena do AIB em estacas utilizando-se concentrações diluídas seja utilizada, aparentemente o método de imersão rápida tem proporcionado melhores resultados. Tofanelli et al. (2002) trataram estacas lenhosas de pessegueiro das cultivares Delicioso Precoce, Jóia 1 e Okinawa com dois métodos de aplicação de AIB (imersão rápida: 0, 1250, 2500 e 3750 mg.L L $^{-1}$ de AIB por 5 segundos e imersão lenta: 0, 100, 200 e $300 \mathrm{mg} . \mathrm{L}^{-1}$ de AIB por 24 horas) e também observaram superioridade do método imersão rápida. Antunes et al. (1996) obtiveram maior enraizamento em estacas de pereira (Pyrus calleryana) quando utilizaram soluções concentradas de AIB em comparação às soluções diluídas. Uma das explicações para esses resultados pode ser o efeito do ambiente durante o tratamento de imersão lenta, pois a ausência de um sistema de nebulização, por exemplo, pode ter favorecido a desidratação das estacas e posterior absorção excessiva das soluções de AIB pelas mesmas que, em vez de o regulador estimular, inibiram o enraizamento.

Para a porcentagem de estacas mortas, houve efeito da cultivar e da interação, mas não houve efeito do método de aplicação de AIB. A maior mortalidade de estacas ocorreu na cultivar Delicioso Precoce com o método de imersão lenta e na cultivar Jóia 1 com o método de imersão rápida (Tabela 2).

$\mathrm{O}$ fato de a cultivar Okinawa ter demonstrado as menores taxas de mortalidade pode ser explicado pelo fato de essa cultivar ter obtido maior enraizamento e maior brotação, pois observou-se que aquelas estacas que não enraizaram e não brotaram encontravam-se mortas. As estacas não enraizadas e não brotadas não possuiam os principais órgaos de absorção de água (raiz e folha) e, por isso, ressecavam e morriam.
TABELA 2 - Porcentagem de estacas mortas de pessegueiro cvs. Delicioso Precoce, Jóia 1 e Okinawa, tratadas com imersão lenta e rápida de diferentes concentrações de AIB. Botucatu-SP, $2002^{(1)}$.

\begin{tabular}{lcc}
\hline \multirow{2}{*}{ Cultivar } & \multicolumn{2}{c}{ Estacas mortas (\%) } \\
\cline { 2 - 3 } & \multicolumn{2}{c}{ Método de aplicação de AIB } \\
\cline { 2 - 3 } & Imersão lenta & Imersão rápida \\
\hline Delicioso precoce & $77,2 \mathrm{aA}$ & $64,7 \mathrm{aB}$ \\
Jóia 1 & $50,7 \mathrm{bB}$ & $76,1 \mathrm{aA}$ \\
Okinawa & $6,2 \mathrm{cA}$ & $5,8 \mathrm{bA}$ \\
\hline
\end{tabular}

${ }^{(1)}$ Médias seguidas por letras minúsculas na coluna $\mathrm{e}$ maiúsculas na linha diferem entre si pelo teste Duncan ao nível de $5 \%$ de significância.

O maior percentual de enraizamento $(23,1 \%)$ e o maior número de raízes (1,7 raiz) foram obtidos com $3750 \mathrm{mg} . \mathrm{L}^{-1}$ de AIB, enquanto o maior comprimento de raiz $\left(1,53 \mathrm{~cm}\right.$ ) foi obtido com 2757,1 mg.L -1 $^{-1}$ (Figuras 1, 2 e 3 , respectivamente).

Antunes et al. (1996) também demonstraram comportamento similar em estacas de pereira, pois obtiveram nas variáveis de maior relevância para a produção de mudas em estacas (enraizamento, número e comprimento de raiz) melhores resultados com o método de imersão rápida, em comparação com o método de imersão lenta.

O maior percentual de estacas brotadas $(73 \%)$ foi obtido pela cultivar Okinawa com $140 \mathrm{mg} \mathrm{L}^{-1}$ de AIB (Figura 4). A maior brotação observada nas estacas da cultivar Okinawa pode ser explicada pelo maior percentual de estacas enraizadas obtido por essa cultivar, pois durante a coleta dos dados observou-se que as estacas que enraizaram, normalmente, emitiram brotações.

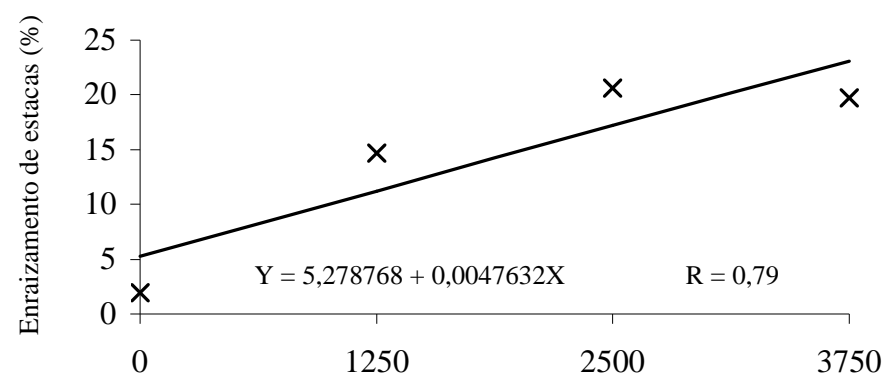

$\mathrm{AIB}\left(\mathrm{mg} \mathrm{L}_{1}\right)$

FIGURA 1 - Porcentagem de enraizamento de estacas semilenhosas de pessegueiro cvs. Delicioso Precoce, Jóia 1 e Okinawa, tratadas com diferentes concentrações de AIB. Botucatu-SP, 2002.

Ciênc. agrotec., Lavras. V.27, n.5, p.1031-1037, set./out., 2003 


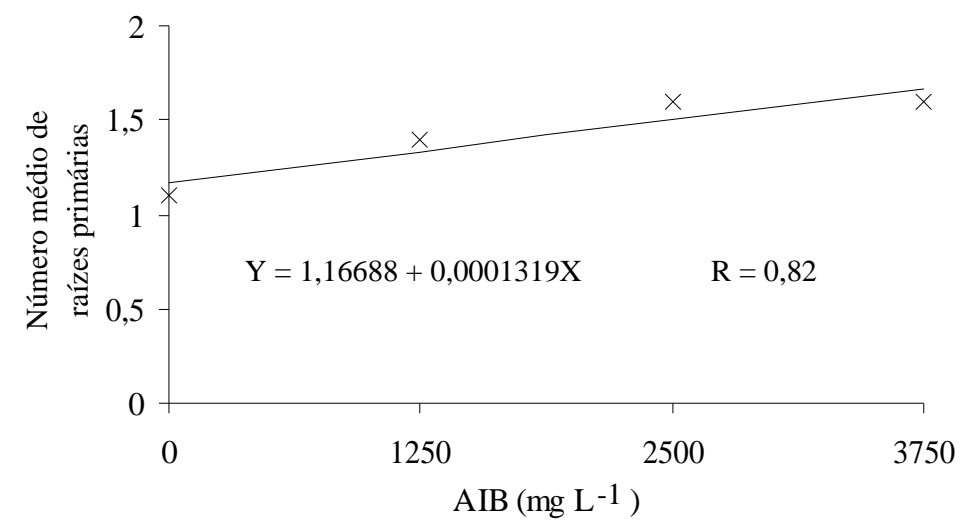

FIGURA 2 - Número médio de raízes primárias em estacas semilenhosas de pessegueiro cvs. Delicioso Precoce, Jóia 1 e Okinawa, tratadas com diferentes concentrações de AIB. Botucatu-SP, 2002.

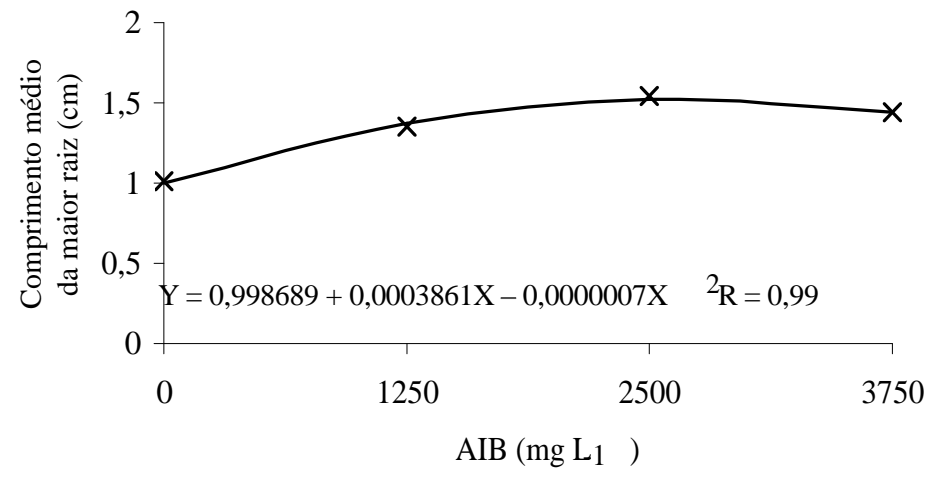

FIGURA 3 - Comprimento médio da maior raiz em estacas semilenhosas de pessegueiro cvs. Delicioso Precoce, Jóia 1 e Okinawa, tratadas com diferentes concentrações de AIB. Botucatu-SP, 2002.

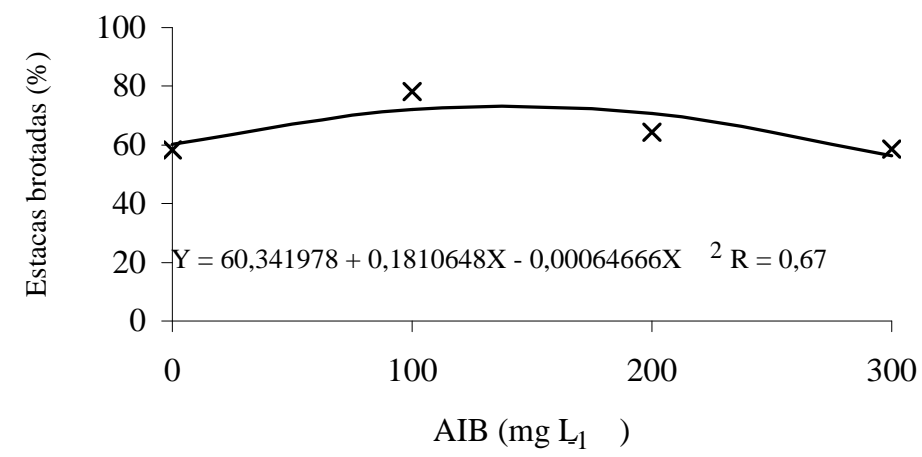

FIGURA 4 - Porcentagem de brotação em estacas semilenhosas de pessegueiro cv. Okinawa, tratadas com diferentes concentrações de AIB. Botucatu-SP, 2002.

Ciênc. agrotec., Lavras. V.27, n.5, p.1031-1037, set./out., 2003 


\section{CONCLUSÕES}

Nas condições em que o experimento foi conduzido, pode-se concluir que:

a) As estacas semilenhosas do porta-enxerto Okinawa apresentaram maior enraizamento, brotação, formação de calo, número e comprimento de raiz e menor morte;

b) A imersão rápida em AIB proporciona os melhores resultados para o enraizamento de estacas semilenhosas das cultivares de pessegueiro;

c) Em razão das baixas porcentagens de enraizamento obtidas, não se recomenda a propagação vegetativa em estacas semilenhosas das cultivares de pessegueiro Delicioso Precoce, Jóia 1 e Okinawa.

\section{AGRADECIMENTOS}

Ao engenheiro agrônomo Emmanuel Afonso Souza Moraes, diretor do Departamento de Sementes, Mudas e Matrizes da CATI, Itaberá (SP), pelo fornecimento do material de pesquisa, e aos funcionários, pelos serviços prestados durante a estada nessa repartição. À coordenadoria de Aperfeiçoamento de Pessoal de Nível Superior (CAPES), pelo apoio financeiro.

\section{REFERÊNCIAS BIBLIOGRÁFICAS}

ANTUNES, L. E. C.; HOFFMANN, A.; RAMOS, J. D.; CHALFUN, N. N. J.; OLIVEIRA JÚNIOR, A. F. de. Efeito do método de aplicação e de concentrações do ácido indolbutírico no enraizamento de estacas semilenhosas de Pyrus calleryana. Revista Brasileira de Fruticultura, Cruz das Almas, v. 18, n. 3, p. 371-376, dez. 1996.

AVERY, J. D.; BEYL, C. B. Propagation of peach cuttings using foam cubes. HortScience, Alexandria, v. 26, n. 9, p. 1152-1154, Sept. 1991.

BIASI, L. A.; STOLTE, R. E.; SILVA, M. da S. Estaquia de ramos semilenhosos de pessegueiro e nectarina. Revista Brasileira de Fruticultura, Jaboticabal, v. 22, n. 3, p. 421-425, dez. 2000.

CHAlFUN, N. N. J.; HOFFMANN, A. Propagação do pessegueiro e da ameixeira. Informe Agropecuário, Belo Horizonte, v. 18, n. 189, p. 23-29, 1997.

CHALFUN, N. N. J.; PASQUAL, M.; RAMOS, J. D.; LIMA, P. C.; CHALFUN JÚNIOR, A.; SILVA, T. das G. Efeito do anelamento e diferentes dosagens do ácido indolbutírico na propagação de estacas caulinares do pessegueiro "Okinawa". Revista Brasileira de Fruticultura, Cruz das Almas, v. 16, n. 1, p. 119-126, 1994.
COUTINHO, E. F.; MIELKE, M. S.; ROCHA, M. S.; DUARTE, O. R. Enraizamento de estacas semilenhosas de fruteiras nativas da família myrtaceae com o uso do ácido indolbutírico. Revista Brasileira de Fruticultura, Cruz das Almas, v. 13, n. 1, p. 167171, out. 1991.

COUVILLON, G. A.; EREZ, A. Rooting, survival and development of several peach cultivars propagated from semi-hardwood cuttings. HortScience, Alexandria, v. 15, n. 1, p. 43-44, Feb. 1980.

DUTRA, L. F.; KERSTEN, E.; FACHINELLO, J. C. Época de coleta, ácido indolbutírico e triptofano no enraizamento de estacas de pessegueiro. Scientia Agrícola, Piracicaba, v. 59, n. 2, p. 327-333, abr./jun. 2002.

DUTRA, L. F.; SCHWENGBER, J. E.; TONIETTO, A.; KERSTEN, E. Enraizamento de estacas de pessegueiro (Prunus persica (L.) Batsch). Revista Brasileira de Agrociência, Pelotas, v. 5, n. 2, p. 9395, maio/ago. 1999.

FACHINELLO, J. C.; KERSTEN, E.; SILVEIRA JÚNIOR, P. Efeito do ácido indolbutírico na percentagem de estacas lenhosas enraizadas e na obtenção de mudas de pessegueiro (Prunus persica (L.) Batsch). In: GONGRESSO BRASILEIRO DE FRUTICULTURA, 7., 1984, Florianópolis. Anais... Florianópolis: Sociedade Brasileira de Fruticultura, 1984. p. 1088-1096.

FINARDI, N. L. Método de propagação e descrição de porta-enxertos, In: MEDEIROS, C. A. B.; RASEIRA, M. do C. B. (Eds.). A cultura do pessegueiro. Pelotas: EMBRAPA/CNPAT, 1998. cap. 1, p. 100-128.

HOFFMANN, A.; CHALFUN, N. N. J.; ANTUNES, L. E. C.; RAMOS, J. D.; PASQUAL, M.; SILVA, C. R. de R e. Fruticultura comercial: propagação de plantas frutíferas. Lavras: UFLA/FAEPE, 1996. 319 p.

KLUGE, R. A.; SCARPARE FILHO, L. A.; JACOMINO, A. P. A cultura do pessegueiro: recomendações para o cultivo em regiões subtropicais. Piracicaba: _ ESALQ, 2001. Disponível em: 4http://www.ciagri.usp.br/ rakluge/Pềssego.html y. Acesso em: 15 jan. 2002.

OKIE, W. R. Rapid multiplication of peach seedlings by herbaceous stem cuttings. HortScience, Alexandria, v. 19 , n. 2, p. 249-251, 1984. 
RUFATO, L.; KERSTEN, E. Enraizamento de estacas de pessegueiro (Prunus persica (L.) Batsch), cvs Esmeralda e BR2, submetidas à estratificação e ao ácido indol-butírico. Revista Brasileira de Fruticultura, Jaboticabal, v. 22, n. 2, p. 191-194, ago. 2000.

TOFANELLI, M. B. D. Enraizamento de estacas lenhosas e semilenhosas de cultivares de pessegueiro em diferentes concentrações de ácido indol-butírico. 1999. 87 p. Dissertação (Mestrado em Fitotecnia) Universidade Federal de Lavras, Lavras, 1999.
TOFANELLI, M. B. D.; CHALFUN, N. N. J.; HOFFMANN, A.; CHALFUN JÚNIOR, A. Uso do ácido indol-butírico na propagação de cultivares-copa de ameixeira através de estacas lenhosas. Científica Rural, Bagé, v. 6, n. 1, p. 115-121, jan./jul. 2001.

TOFANELLI, M. B. D.; ONO, E. O.; RODRIGUES, J. D. Potencial de enraizamento de estacas lenhosas de pessegueiro tratadas com ácido indol-butírico em diferentes concentrações e métodos de aplicação. Revista Brasileira de Agrociência, Pelotas, v. 8, n. 2, p. 159-160, maio/ago. 2002. 